\title{
La función del paisaje como recurso territorial turístico en zonas de interior
}

\author{
Francisco CEBRIÁN ABELLÁN \\ Departamento de Geografía y Ordenación del Territorio \\ Universidad de Castilla-La Mancha \\ Francisco.Cebrian@uclm.es
}

Recibido: 7 de abril de 2013

Enviado a evaluar: 17 de abril de 2013

Aceptado: 3 de octubre de 2013

\begin{abstract}
La prosperidad y el bienestar son objetivos conscientes y a la vez predeterminados para las luchas del hombre; esto produce una inevitable, profunda y aterradora contradicción, porque al buscar la prosperidad y el bienestar, la humanidad se despoja de muchas de sus mejores cualidades.

Mo Yan -Premio nobel de Literatura 2012(Sorgo Rojo, El Alep Editores, pp 477)
\end{abstract}

\section{RESUMEN}

Al medio rural se añaden nuevas dimensiones y funciones, dentro del posproductivismo, asociadas a unos espacios que cuentan con recursos territoriales no deslocalizables. El turismo rural es especialmente dinámico en algunos espacios, apoyado en actividades recreativas y en el uso del paisaje como elementos predominante. Este trabajo presta atención al proceso de puesta en valor del paisaje por parte de turistas y administraciones. Para analizar sus manifestaciones se ha seleccionado una provincia de interior, la de Albacete, que ha experimentado una fuerte dinámica en esta modalidad en la última década, y en la que los paisajes del agua se convierten en protagonistas.

Palabras clave: paisaje, turismo rural, desarrollo local.

\section{The role of landscape as a tourist territorial resource in inland areas}

\begin{abstract}
In rural adding new dimensions and functions within the posproductivismo, associated with spaces that have land resources can not be relocated. Rural tourism is especially dynamic you some spaces, supported recreational activities and the use of landscape as predominant elements. This paper pays attention to the process of enhancement of the landscape by tourists and administrations. To analyze its manifestations has been selected inland province, the de Albacete, which has experienced strong momentum in this mode in the last decade, and in which water landscapes become protagonists.
\end{abstract}

Key words: landscape, rural tourism, local development. 


\section{LOS PROCESOS DE CAMBIO EN EL MEDIO RURAL: DE LA VOCACIÓN AGROPECUARIA A LA INCIPIENTE CONVERSIÓN EN ESPACIOS TURÍSTICOS}

El término rural, de difícil precisión, hace referencia a la débil densidad de población, al atraso socioeconómico y a una fuerte identidad local, sustentada en la herencia histórico-cultural. Se suma a esta visión negativa la presencia de políticas propias de apoyo organizadas desde las estrategias de la Unión Europea. Pero se está produciendo un cambio en las percepciones, las políticas, las funciones y el uso social del medio rural. Ha habido una transformación profunda desde su originaria vocación agropecuaria y forestal (que ha marcado las dinámicas y sobre todo ha condicionado su base económica, sectorialmente reducida y vinculada al sector primario), a la plurifuncionalidad, que asigna un protagonismo creciente al medio rural. Se han incorporado actividades vinculadas al sector servicios que han contribuido a alterar esas estructuras. Las zonas rurales están cambiando, y cada vez tiene más fuerza la idea de que son "espacios de actividad, de cultura, de producción de bienes y servicios, que contribuyen también al bienestar del conjunto de la sociedad por la respuesta que pueden dar a las demandas sociales en materia de contacto con la naturaleza, acogida, diversidad del paisaje..." (Propuesta para una Política Europea de Desarrollo 2007-13). Estos nuevas visiones han posibilitado un escenario de clara revalorización de la ruralidad (Cebrián, A.; 2003), vinculada ahora al ocio y al turismo (Pillet, F.; 1997: 251).

Ha sido desde los años noventa del siglo pasado cuando se ha despertado el interés creciente por el turismo rural, fruto de una confluencia de factores que han favorecido una mirada, más abierta y diversificada, a las nuevas posibilidades de los espacios rurales en un contexto de globalización creciente. En la sociedad posmoderna desempeñan funciones diferentes las zonas de montaña especialmente, entre las que cobran un papel relevante aspectos culturales y sociales. El resultado ha sido una revalorización selectiva de lo local, que ha impulsado estrategias de desarrollo, con la incorporación de nuevas actividades complementarias a las estructuras económicas tradicionales.

Esparcia y Noguera presentaban hace más de una década lo que entendían como factores determinantes del desarrollo en el medio rural, y entre ellos citaban tres: la especialización en actividades favorecidas por coyunturas, la presencia de ventajas comparativas en términos de comunicaciones o recursos, y la especialización en actividades innovadoras (Esparcia, J.; Noguera, I: 1999: 232). Esas circunstancias han servido para explicar la aparición, y en ocasiones la consolidación, de un turismo rural apoyado en recursos no deslocalizables. Es cierto que ha estado favorecido por los impulsos institucionales, y al amparo de una demanda creciente en esa modalidad turística. Aparece por tanto como una actividad que aprovecha los recursos endógenos del medio rural, y que se convierte en un instrumento de desarrollo local, en el que participan redes sociales, actividades económicas y el propio soporte socioterritorial. Es en definitiva un instrumento de modernización de un sector terciario tradicional, que introduce nuevas actividades y valor añadido. 
En el caso español ha habido una movilización de actores y de recursos (Cebrián, A.; 2003: 63), que ha venido de la mano sobre todo de los grupos de desarrollo local, nutridos de fondos procedentes de las comunidades autónomas, del Estado central y de la Unión Europea. Los protagonistas del impulso han sido sobre todo los programas LEADER, orientados a prestar ayudas y atenciones para dar respuesta a unos acusados problemas socioeconómicos y territoriales, $\mathrm{y}$ en los que el turismo rural ha tenido un papel relevante. El programa FEADER (2007-13) mantiene como objetivo diversificar la actividad económica y presta al turismo una atención especial. Pero el turismo no se ha implantado de manera generalizada. Su aparición ha sido selectiva y se ha dado en territorios donde confluyen la presencia de recursos territoriales turísti$\cos$ (y sobre todo paisajísticos), y donde han aparecido iniciativas empresariales dirigidas a la creación de establecimientos de acogida, en zonas en las que se han dado oportunidades de negocio para esta actividad. Ha proliferado en aquellos territorios en los que se ha producido un aumento de la demanda, donde los turistas han entendido los espacios rurales como escenarios vivenciales y de recreo, de alternativa a una realidad urbana marcada por el estilo de vida acelerado, en el que cobra valor el contacto con paisajes rurales poco alterados.

El interés por la temática es evidente en el mundo académico. Desde finales de los años noventa han aparecido numerosos trabajos desde perspectivas y posiciones diversas. En el ámbito disciplinar de la Geografía han visto la luz obras colectivas (Valenzuela, M; 1997). A partir de un enfoque eminentemente cartográfico se han editado varios atlas dedicados expresamente a prestar atención a la modalidad de turismo rural, como el Atlas de turismo rural de Castilla-La Mancha (Sancho, J.; Panadero, M.; 2004) y el Atlas del turismo rural de España (Vera, F.; Sancho, J.; 2008). Pero también en la última década ha visto la luz un nutrido corpus de trabajos de investigación sobre el turismo rural (en sus distintas manifestaciones) en revistas especializadas (algunos de los referentes son la revista Cuadernos de Turismo editada por la Universidad de Murcia; la revista de Análisis Turístico, editada por AECIT desde 2006; o la recién aparecida revista de Investigaciones Turísticas del Instituto Universitario de Investigaciones Turísticas de la Universidad de Alicante). Han aparecido también números monográficos dedicados al turismo rural en revistas de Geografía (Serie Geográfica $n^{\circ} 15$ de 2009). Se ha incorporado un apartado específico al turismo rural dentro del monográfico que edita anualmente la Asociación Española de Expertos Científicos en Turismo (AECIT) y que aparece bajo la denominación genérica de "la actividad turística española".

Una prueba de su importancia creciente está en el aumento del número de turistas, de visitantes y de alojamientos. Desde el año 2001 el INE se ha hecho eco de esta realidad, y considera y analiza en sus estadísticas de forma individualizada al turismo rural. Se trata de un interés justificado, ya que desde comienzos de siglo ha aumentado considerablemente su participación en los diferentes aspectos cuantificables desde el punto de vista de la demanda y los establecimientos. Según el INE en 2001 se contabilizaron 1.210 .891 viajeros y 3.660 .815 pernoctaciones en España. Estos valores se han duplicado hasta 2011 (en este último año aparecían recogidos en las es- 
tadísticas 2.715.986 de viajeros y de 7.696.369 pernoctaciones dentro de la modalidad de turismo rural). En ese mismo periodo ha crecido el número de establecimientos desde los 5.497 (y 42.925 plazas) en 2001 a 14.796 (y 133.594 plazas). Este fenómeno, que es de carácter nacional, ha tenido una especial dinámica en los espacios de interior, a resguardo, en todos los sentidos -positivos y negativos-, de los efectos del turismo de masas. En el caso de Castilla-La Mancha el crecimiento ha sido más acentuado, ya que ha pasado de tener 58.329 viajeros y 148.905 pernoctaciones en 2001 a 173.079 viajeros y 401.826 pernoctaciones en 2011 (se ha triplicado en estos años). En el número de plazas Castilla-La Mancha pasaba de 352 establecimientos y 2.442 plazas en 2001 a 1.465 establecimientos y 12.128 plazas en 2011 (INE) (se ha multiplicado por cuatro en este periodo). Pero no ha crecido solo desde la óptica de los alojamientos reglados; también lo ha hecho como fenómeno de las segundas residencias o como turismo oculto, de difícil cuantificación, pero que es evidente en algunos espacios de interior (García, J.A.; 2009).

\section{LAS RELACIONES ENTRE TURISMO RURAL Y PAISAJE}

Abrir el debate entre las relaciones entre turismo y paisaje hace obligado prestar atención, aunque sea de forma sintética, al marco conceptual en el que se desenvuelve el turismo rural y el paisaje. En relación a la definición de turismo no se ha logrado un acuerdo consensuado (Pulido, J.I.; 2008: 22). En parte porque tiene implicaciones de distinta naturaleza (socioeconómicas, socioculturales, territoriales y antropológicas). También porque está sujeto a cambios internos (en su estructura organizativa, y en su capacidad de generar producto) y de la demanda (cada vez más flexible y cambiante). Los procesos de transformación han generado un turismo más especializado e intensivo (Bosch, R. et alt., 1998), que tiene repercusión indudable sobre el espacio en el que se produce, y que ha llevado a nuevos desarrollos y percepciones de los lugares (Vera,J.F.; 1997). Pero ese turismo cambia y genera una relación imprecisa entre ocio y turismo, que se ve sujeta a efectos perniciosos por los problemas derivados de la congestión y en el que se incorporan nuevos destinos y productos (Pulido, J.I.; 2008: 26).

Los conceptos de turismo, de turismo rural y paisaje se prestan a interpretaciones y están sometidos a un debate profundo. Existe coincidencia en asumir que, desde el punto de vista territorial, el turismo se desarrolla en paisajes rurales y naturales. Estos turismos rurales (porque son varias las modalidades que participan y que se desarrolla en este ámbito) están asociados a unos tipos de alojamientos específicos, a una demanda con unos caracteres concretos, y a unas determinadas tipologías de productos (López, F.; 2008: 43-44). Esta realidad nos lleva a prestar atención a una de las partes esenciales del proceso: los recursos territoriales turísticos en el medio rural, y en especial al papel que desempeña el paisaje.

En el proceso de construcción de los turismos rurales confluyen tres elementos fundamentales: equipamientos, recursos y demanda. En el caso de los recursos, que son la materia prima que alimenta al sistema turístico, hay un protagonismo indiscutido del paisaje. Existe una comunión estrecha, y con unas interdependencias acusadas, 
entre turismo rural y paisaje. Las razones que justifican esta última afirmación se explican porque dentro de los turismos en el medio rural las motivaciones principales de la demanda están asociadas al disfrute del medio ambiente en las diferentes modalidades: turismo ecológico (disfrute de la naturaleza de forma activa) (Ivars, J.A.; 2000), turismo verde (actividades turísticas y deportivas en el medio natural) (Juan, F. y Solsona, J.; 2000: 10-11), agroturismo, turismo deportivo, turismo de salud, turismo rural-cultural (López, F.; 2008: 45). Todas tienen en común que el motivo de atracción o el soporte territorial en el que se desarrollan son los paisajes rurales, que se convierte no solo en escenario sino en el principal objeto de consumo.

Es importante por ello hacer algunas anotaciones al concepto, tan geográfico, del paisaje. El término tiene una doble componente: la natural y la social. Ha surgido un cuerpo teórico que ha centrado la atención en aspectos objetivos del paisaje, entendido como unidades espaciales asociadas a la estructura física del territorio, sobre la que la acción antrópica ha ido dejando una huella secular. Pero junto a propuestas de definición objetivas, han aparecido otras en las que los valores subjetivos son dominantes, asociados en este caso a significados, representaciones, cualidades y valores, que vienen en este caso expresados a través de sentimientos de identidad sobre esos territorios (Martínez de Pisón, ; 2005: 46). Estas dimensiones, la natural y la cultural, están estrechamente vinculadas (Ortega, N.; 2004), son consecuencia de la actuación conjunta de la naturaleza y la acción del hombre, de la que resultan valores estéticos, naturales y ecológicos, productivos, históricos, usos sociales, espirituales y mitológicos, simbólicos e identitarios (Nogué, J. y Sala,; 2006: 21).

El interés por el paisaje llevó al Consejo de Europeo a aprobar hace más de una década el Convenio Europeo del Paisaje (2000). La definición aportada por este Convenio indica que "por paisaje se entenderá cualquier parte del territorio tal como la percibe la población, cuyo carácter sea el resultado de la acción y la interacción del factores naturales y humanos", y su importancia estriba en que contribuye a la formación de culturas locales, se considera elemento importante en la calidad de vida de las poblaciones, es fuente de recursos económicos, y está sujeto a cambios profundos asociados al abandono o a los nuevos usos (Convenio Europeo del Paisaje: 2).

Estos aspectos lo ponen en relación con las posibilidades de aprovechamiento de los espacios rurales, donde el paisaje se convierte en recurso, en elemento de consumo, pero también en potencial territorial y activo importante para el turismo rural. Algunos paisajes, que son resultado de actividades agropecuarias o forestales, cobran un valor creciente, y se incrementa su precio social. En ocasiones son parajes naturales con encanto, de visita obligada y con capacidad de dar identidad social a quien los recorre. En otras son simplemente paisajes invisibles de la historia, de la memoria, del pasado, que están en la frontera entre el ayer y el hoy, y que adquieren protagonismo para algunas funciones y actividades recreativas y turísticas. En ocasiones por el simple valor real o simbólico del paisaje. En otros casos porque van acompañados de acontecimientos culturales programados (tradicionales o de nuevo cuño).

La mayor parte de las actuaciones dirigidas a corregir y conservar el paisaje se han concentrado en los espacios protegidos, a los que se supone un valor ambiental y 
natural elevado. En España se han sucedido en los últimos años documentos y leyes en las que el paisaje cobra protagonismo. Eso supone dar a algunos de ellos la condición de patrimonio, por el valor asumido y compartido por la colectividad y por el fuerte componente cultural (Muñoz, F.; 2010: 325). Pero también es cierto que un acercamiento masivo a la naturaleza implica trasladar a esos territorios parte de los conflictos y problemas de la sociedad posindustrial y consumista.

Por todo ello se ha prestado atención creciente al paisaje. Se ha elaborado una caracterización de los paisajes españoles (Atlas de los paisajes de España, elaborado por el Ministerio de Medio Ambiente); se ha preparado un Plan Nacional del Paisaje Cultural (Ministerio de Cultura); la Ley de Patrimonio Natural y Biodiversidad (Ley 42/2007 de 13 de diciembre) asume la definición de paisaje y establece figuras de protección; la Ley de Desarrollo Sostenible del Medio Rural (Ley 45/2007 de 13 de diciembre) introduce el paisaje como recurso y como tarea de conservación; la Ley del Suelo (Ley 8/2007 de 28 de mayo) incluye expresamente al patrimonio cultural y al paisaje; o el Reglamento de Planificación Hidrológica (RD 907/2007 de 6 de julio) contempla al paisaje entre sus elementos de aplicación (Ortega, M.; 2010: 329-335).

Aparte de la normativa de carácter ambiental en España, como reacción a las negativas consecuencias del abandono de los espacios rurales y del urbanismo expansivo, se viene reivindicando una nueva cultura que aboga por "un territorio bien gestionado -como contenedor de valores ecológicos, culturales y patrimoniales... y un activo económico de primer orden". Se pide a los poderes públicos hacer un uso acorde de los instrumentos de planificación territorial y urbana con participación y proyección social (Manifiesto por una Nueva Cultura del Territorio). Esta misma idea, desde otra óptica, aparece recogida en el Libro Verde sobre la Cohesión Territorial (2008), en el que se apuesta por el desarrollo territorial equilibrado y sostenible a partir del desarrollo de los activos que comprenden el capital fijo, humano y social, pero también de los recursos naturales de los territorios, y que se conocen como capital territorial. Todo este cuerpo normativo y teórico que se ha sucedido en torno a la idea y concepto de paisaje está impulsando la consideración y actuación sobre éste. Algunas comunidades autónomas han tomado conciencia de la situación y han comenzado el proceso de regulación y aprobación de leyes autonómicas de paisaje (las pioneras han sido la Comunidad Valenciana -Ley 4/2004 de 30 de junio, la Catalana con la Ley de Ordenación del Territorio y Protección del Paisaje de Cataluña -Ley 8/2005 de 8 de junio, de Protección, gestión y ordenación del Paisaje-; y Galicia -Ley 7/2008 de 7 de julio de Protección del Paisaje-).

El paisaje se ha convertido en potencial territorial, y por tanto en activo indiscutido para el turismo rural. Cobra un valor creciente, porque hay cada vez mayor interés por el uso de paisajes rurales y naturales de calidad (que son resultado de actividades preturísticas) a los que se asigna un precio social importante. Los visitantes y turistas perciben el mundo rural con mayor complejidad, superando la identificación tradicional de la economía rural, donde al papel de proporcionar productos agrarios se añaden ahora el de facilitar bienes ambientales, paisajísticos y culturales (Olivares, D.; 2008: 162). Por esa razón hay una conciencia creciente dirigida a poner en valor el paisaje y fomentar un uso social responsable. 


\section{LA PUESTA EN VALOR DE LOS PAISAJES TRADICIONALES}

Estamos por tanto en un tiempo de revalorización de los espacios rurales en desuso, de los espacios de reserva, como zonas de ocio. Es el momento de recuperar los residuos territoriales, la geografía de los tiempos muertos (Muñoz, F.; 2010: 319), alejados física, tecnológica y socialmente de los territorios conectados, visibles, luminosos, posmodernos en definitiva, situados en las zonas de influencia más directa de las ciudades y sus sistemas de comunicaciones (convencionales o virtuales). Es en estos territorios invisibles, casi opacos, mal desconectados en definitiva, donde el turismo se convierte en un gran consumidor de paisaje, jugando una doble función: por un lado redescubre y revitaliza algunos paisajes, convirtiéndolos en microdestinos, a los que preserva. Pero también se transforman estructuras tradicionales por la presión intensa de un turismo concentrado en el tiempo y en el espacio, que en ocasiones genera el abandono de las actividades tradicionales que lo han construido (agricultura, ganadería, silvicultura...) o por efecto del creciente uso turístico surgen acusados problemas de degradación ambiental. Pero en todos ellos el paisaje se convierte en recurso y en objeto de consumo. Se trata de un proceso en el que uno de los principales problemas es su valorización y comercialización para que forme parte activa en el producto turístico (Antón, S.; 2005: 2).

Hay que tener presente que el turismo rural en la España interior se apoya mayoritariamente en una demanda de procedencia nacional, heterogénea en su composición y sobre todo de origen urbano. Se asocia a desplazamientos de fines de semana, puentes largos, vacaciones de tipo residencial o estancias en casas de familiares y amigos. Los principales atractivos están asociados al interés creciente por la naturaleza y por espacios rurales para el ocio, o por la existencia de relaciones personales y afectivas entre el turista y el destino. Se trata en definitiva del turista guiado por el acercamiento a la naturaleza (Crosby, A.; 1994) y a la vida rural, que está sensibilizado por el medio ambiente (Pérez, M.; 1997) o es aficionado a las prácticas de las actividades al aire libre (Mesa, M.; 2000). Esto justifica la atención creciente por el paisaje, ya que se está convirtiendo en objeto de deseo por parte de los usuarios (turistas o visitantes), y en las actuaciones de la administración, que intenta ponerlo en valor para su uso turístico.

Estas dos realidades, por un lado el creciente interés de los turistas por el turismo rural y en especial por el paisaje, y por otra parte las actuaciones de diferentes instituciones por impulsar el uso de espacios de valor ambiental o paisajístico destacado, nos han impulsado a prestar atención a las preferencias de los turistas y a las actuaciones de la administración para poder utilizar los espacios y los paisajes rurales en un territorio concreto, la provincia de Albacete, una de las que cuenta con mayor peso dentro de esta modalidad a nivel nacional: Castilla-La Mancha fue en el año 2011 la quinta comunidad por número de viajeros y la séptima en pernoctaciones según la encuesta de ocupación de alojamientos turísticos dentro del Turismo Rural, además de aparecer en tercera posición a nivel nacional en alojamientos y plazas dentro de esta modalidad. Dentro de esta comunidad autónoma la provincia de Albacete es la 
que mayor peso tiene en turismo rural, y queda en la novena posición a nivel nacional en pernoctaciones y en la décima en viajeros (datos de diciembre de 2012; INE, 2013).

\section{EL PAISAJE COMO RECURSO TURÍSTICO EN LA PROVINCIA DE ALBACETE}

\subsection{LAS PREFERENCIAS DE LA DEMANDA}

Los escasos trabajos realizados sobre las preferencias de la demanda en el medio rural en las últimas décadas ponen énfasis en la relación existente entre turismo y paisaje, que se convierte en el elemento de referencia a la hora de seleccionar destinos, y es el primer atractivo valorado. Uno de los estudios pioneros sobre las preferencias de la demanda, realizado a escala nacional por el CSIC a mitad de la década de los años noventa -que es cuando el turismo rural estaba en sus inicios-, apuntaba algunos aspectos que han marcado y siguen definiendo las líneas de actuación de los turistas que apuestan por esta modalidad. Entre las motivaciones aparecían las visitas al lugar de nacimiento o a familiares (50\%) (no hay que olvidar que el medio rural del interior peninsular, que es donde el turismo rural ha cobrado un especial protagonismo, ha sido una tradicional zona de emigración, especialmente desde la década de los años cincuenta del siglo pasado). Esto explica las relaciones afectivas y familiares. Pero junto a esta razón, de carácter turístico-sentimental, aparecía otra que estaba asociada al contacto y disfrute con la naturaleza (31\%) (Bote, V.; 1995).

A escala de la provincia de Albacete las motivaciones de los turistas tienen una fuerte relación con lo que apuntaba la encuesta elaborada por CSIC en 1995 para el territorio nacional. En los años 2005 y 2007 realizó el Servicio de Turismo de la Cámara de Comercio dos estudios (uno era el Estudio del Mercado turístico de la provincia de Albacete, 2005 y el otro se titulaba Análisis comarcal de la oferta turística de Albacete, perspectivas de la demanda) (Cámara de Comercio de Albacete, 2006 y 2008). Son trabajos diferentes, con metodologías distintas y para escalas desiguales. Pese a ello ayudan a poner luz a una realidad fundamental y poco conocida y ahondan en el conocimiento del comportamiento de los turistas en la provincia de Albacete a escala provincial y comarcal.

Del primero se desprende que son "la naturaleza, los paisajes, los lugares" los principales motivadores a la hora de elegir la provincia de Albacete como destino de turismo rural (51\% de las respuestas) seguido de la visita a familiares y amigos (42\% de las respuestas). También aparecen como recursos más conocidos los paisajísticos ( $75 \%$ de los turistas-visitantes conocían el patrimonio natural). Del segundo estudio se extraen también ideas interesantes relacionadas con el valor y uso turístico del paisaje, ya que en este caso destacan como preferencias la "visita a familiares y amigos" (52\%), seguida de "municipios, pueblos y aldeas" (39\%) y en tercer lugar aparare "la naturaleza, los paisajes y los lugares" (31\%). Al margen de la terminología empleada en la formulación de las preguntas, aparece una valoración de los paisajes rurales, más o menos transformados, en los que se da un protagonismo especial a lo cultural y natural asociado al medio rural. La encuesta centraba su análisis en el 
comportamiento de los turistas a escala comarcal (empleando para ello las comarcas Leader: Campos de Hellín, Sierra de Alcaraz y Campo de Montiel, Corredor de Almansa, Mancha Júcar-Centro, Manchuela y Sierra del Segura). Un hecho a destacar es que en las zonas de montaña cobra un protagonismo creciente el valor de los paisajes y la naturaleza como elemento motivador y movilizador de los turistas. Las respuestas de los encuestados indican que el principal atractivo es la naturaleza en la Sierra del Segura (donde se encuentra el Parque Natural de los Calares del Mundo y de la Sima) (49\%), la Sierra de Alcaraz y Campo de Montiel (donde se encuentra el Parque Natural de las Lagunas de Ruidera) (48\%), y la Manchuela (atravesada por un río Júcar que ha labrado profundos cañones de paredes verticales) (40\%). El principal motivo es en la elección del destino la "naturaleza, los paisajes y los lugares".

Se han realizado algunos trabajos de investigación que ayudan a completar, a escala comarcal y municipal, la visión del turista en relación al paisaje. En el caso específico de la Sierra del Segura, al sur de la provincia de Albacete, se han analizado a escala municipal algunos aspectos de la demanda. Entre los aspectos considerados aparecen las preferencias, entre las que el paisaje se convierte nuevamente en protagonista estelar, ya que en las motivaciones están en buena medida asociadas a su calidad y singularidad en algunos enclaves.

\subsection{EL USO TURÍSTICO DEL PAISAJE EN LA PROVINCIA DE ALBACETE}

El interés por desarrollar actividades en el medio rural, y la atención creciente de los turistas hacia el paisaje, ha impulsado la puesta en marcha de iniciativas de recuperación y puesta en valor desde la pasada década, que es cuando comienza a hacerse uso del paisaje como recurso turístico. Parte de este cambio se explica porque se ha acelerado el proceso de declaración de espacios protegidos (con elevado valor ambiental, pero también turístico). También se han recuperado antiguos itinerario y rutas. En lugares estratégicos se han creado miradores y espacios de estancia. En ocasiones estas actuaciones se superponen o son coincidentes, ya que en muchos casos se dan en los mismos espacios protegidos. Pero las más de las veces se dan sobre territorios con valores ambientales elevados pero sin regulación específica. Al proceso de creación de estos instrumentos en la provincia de Albacete prestamos atención en estas páginas, ya que se han convertido en los principales elementos de uso recreativo y consumo turístico de las diferentes unidades de paisaje.

\subsubsection{LOS ESPACIOS PROTEGIDOS}

Como se apuntaba anteriormente, la red de espacios protegidos es un elemento vertebrador fundamental del sistema turístico provincial. Los elementos más representativos son los parque naturales -las más elevadas categorías de protección regionales- (Lagunas de Ruidera y Calar del Mundo y de la Sima), varias reservas naturales (Laguna de los Ojos de Villaverde, Laguna Salada de Pétrola, Saladar de 
Cordovilla, Sierra de Las Cabras), Microrreservas (Ardal y Tinjarra, Arenales de Caudete, Cerro de la Rala, Cuerda de la Melera, Estrecho del Hocino, La Molata y los Batanes, Laguna de Alboraj, Peñas Coloradas, Saladar de Agramón, Salinas de Pinilla, Yesares de Hellín), y monumentos naturales (Laguna del Arquillo, Pitón Volcánico de Cancarix) (http://pagina.jccm.es/medioambiente/espacios_naturales/listado.htm, consulta: 3-3-2013). Los parques naturales, que se convierten en recursos básicos para el turismo rural y son los principales ámbitos de consumo paisajístico por el número de visitas que reciben al año. Las otras figuras tienen una relevancia menor desde el punto de vista de la afluencia turística, y prueba de ellos es que la administración no ha prestado atención al número de visitas que se reciben.

El Parque Natural de las Lagunas de Ruidera obtuvo esta declaración en el año 1979 (Real Decreto 2610/1979, de 13 de julio). Cuenta con una superficie de casi cuatro mil hectáreas, de las que una parte están en la provincia de Albacete. El parque protege el sistema hidrogeológico y biogeográfico del Alto Guadiana. El principal elemento de referencia lo forma una serie de lagunas escalonadas y represadas por barreras tobáceas, cuya génesis está asociada a un acuífero somero. Su valor geomorfológico, botánico y faunístico explican que esta zona húmeda tenga una gran capacidad de atracción. Los paisajes, poco transformados, se han convertido en un recurso turístico, con una afluencia importante de turistas motivados por modalidades de naturaleza y de deportes al aire libre, pero que ha dejado un modelo turístico marcado por una acusada estacionalidad. En este caso las estimaciones apuntan al medio millón al año, repartidos en los pocos núcleos que existen en el entorno, y a lo largo del rosario de establecimientos localizados siguiendo los ejes viarios.

En noviembre de 2002 se publicaba el Plan de Ordenación de Recursos Naturales de los calares y cabeceras de los ríos Mundo, Tus y Guadalimar, donde se reconoce "la importancia geomorfológica botánica y paisajística de la zona conocida como Los Chorros del Río Mundo. A estos valores naturales se une el interés turístico, lo que motivó la realización de un acuerdo con los propietarios para declarar esta zona como Zona de Protección Especial... El objeto de la iniciación del citado expediente es asegurar la conservación de los valores naturales de la zona, procurando su restauración cuando se encuentren degradados, así como fomentar los aprovechamientos tradicionales y el turismo de naturaleza de forma que queden sentadas las bases del desarrollo sostenible" (Decreto 160-2002 de 12-11-2002, DOCM n ${ }^{\circ} 159$ de 23 de diciembre de 2002; pp 18705-18706). Afecta a seis municipios de la provincia de Albacete y tiene una superficie de 19.192 Has. Dentro de este espacio protegido, tiene un especial protagonismo el paraje conocido como "Los Chorros", próximo al histórico enclave minero industrial de Riopar, al que se le puede considerar como un microdestino con una considerable capacidad de atracción turística, con una afluencia estimada que va de los doscientos cincuenta a los trescientos mil visitantes año (periodo 2008-2011) (Fuente: Parque Natural de los Calares del Mundo y de la Sima). 


\subsubsection{EJEMPLOS DE EJES DE PENETRACIÓN TURÍSTICA AL TERRITORIO Y AL PAISAJE}

\section{a) La Vía Verde de Alcaraz}

En el año 1993 el entonces Ministerio de Obras Públicas, Transporte y Medio Ambiente, en colaboración con Renfe, Feve y Fundación de Ferrocarriles Españoles, puso en marcha el programa de Vías Verdes. Posteriormente se le han sumado otros actores institucionales. Desde entonces se han recuperado para su disfrute numerosos trazados de ferrocarriles olvidados y en desuso, destinados ahora al ocio, la práctica de actividades deportivas y el disfrute de la naturaleza. El objeto de las actuaciones va dirigido a impulsar el turismo rural desde la óptica de la mejora de la movilidad, la educación ambiental y el fomento de los turismos alternativos (Fundación Ferrocarriles Españoles; 2008: 2 y 24). En el caso de la provincia de Albacete la recuperación del antiguo Baeza-Utiel era, en parte, uno de los recorridos de la cuestionada Ruta de Don Quijote, impulsada por la Junta de Comunidades de Castilla-La Mancha y en el que participa la Diputación Provincial de Albacete. El trazado sigue el recorrido de un antiguo ferrocarril (que nunca llegó a entrar en funcionamiento). Las obras de acondicionamiento se realizaron entre 2003 y 2006. El tramo finalmente recuperado va desde la ciudad de Albacete hasta los límites con la provincia de Jaén. Otra parte surgía de la iniciativa de recuperación de Vías Verdes.

Esta razón explica que parte del trazado tenga el tratamiento de Ruta de Don Quijote, y que haya sido recuperada por la Junta de Comunidades de Castilla-La Mancha y la Fundación Ferrocarriles Españoles. Tiene $57 \mathrm{Km}$ de recorrido (algo más de la mitad del total de la Vía Verde), y va desde el núcleo de El Jardín hasta la Villa de Alcaraz. El otro tramo va desde las cercanías de la ciudad de Albacete hasta el núcleo de El Jardín, y tiene $49 \mathrm{Km}$ de longitud. En este caso ha sido la Diputación Provincial de Albacete la responsable de su recuperación y puesta en valor. Como resultado queda una vía acondicionada para el senderismo, el cicloturismo o las rutas a caballo, que sigue el recorrido del río Balazote y Jardín, entre las ciudades de Albacete y Alcaraz. Quedan ahora caminos compactados y acondicionados, túneles iluminados, áreas de descanso, aparcamientos, señalización dentro y fuera del recorrido, reforestación con especies autóctonas, obras de drenaje, pasos de fauna, paneles interpretativos... Incluso en algunos sectores se han realizado tareas de reconstrucción de paisajes, con reforestaciones en sus márgenes, y con instalación de barandillas de madera en los laterales con terraplenes. En su recorrido la Vía Verde, que va paralela al río Jardín, atraviesa diferentes unidades de paisaje, algunas de vega y otras de montaña media poco antropizada y convertida en paisajes olvidados por efecto de los procesos emigratorios de la últimas décadas. Ahora son territorios que comienzan a recobrar valor por su función turística, de ocio o deportiva. Prueba de ello es la aparición de alojamientos rurales y algún que otro museo etnográfico a lo largo de su recorrido.

Con objeto de conectar la Vía Verde con algunos de los espacios protegidos situados en sus inmediaciones, se han creado ramificaciones que han permitido incremen- 
tar el uso turísticos y recreativo de algunos enclaves de elevado valor paisajístico (en las normativas reguladoras de todos ellos aparece expresamente recogido la noción de elevado valor paisajístico) (Reserva Natural de la Laguna de los Ojos de Villaverde, Monumento Natural de la Laguna del Arquillo, Microrreserva del Estrecho del Hocino).

Con un trazado en paralelo a la Vía Verde aparece un proyecto de actuaciones, proyectado en el año 2009 por la Confederación Hidrográfica del Júcar, que tiene por objeto la restauración fluvial del tramo medio-alto del Río Jardín, y su integración con el entorno de la Laguna de Villaverde. Entre los objetivos del proyecto se contemplan actuaciones de adecuación y recuperación ambiental (vegetación natural de ribera, eliminación de azudes y limpieza de cauce), y el fomento del uso racional el cauce y sus riberas desde el punto de vista didáctico (está prevista la instalación de señales informativas a lo largo del recorrido y en las inmediaciones de los núcleos habitados y en los puntos de conexión con la Vía Verde (Confederación Hidrográfica del Júcar; 2009: 36).

\section{b) Los Canales de María Cristina}

La Confederación Hidrográfica del Júcar ha realizado, en las inmediaciones de la ciudad de Albacete, trabajos de limpieza y acondicionamiento de los históricos caminos de servicio de los Canales de María Cristina. Ha supuesto un proceso de recuperación de una red viaria ramificada y arborescente que conectaba un conjunto de antiguas lagunas, ahora desecadas, que se drenaron mediante cauces artificiales que vertían las aguas estancadas al río Júcar (todavía llevan agua ocasionalmente). Ahora son caminos acondicionados para la práctica del senderismo o el cicloturismo, y que se han prolongado hasta el cercano núcleo de Valdeganga. El trazado se ha protegido con barandillas laterales de madera, se han creado lugares de estancia y descanso, y en algunos lugares se han colocado paneles interpretativos y se han realizado reforestaciones en las riberas. Los antiguos canales de María Cristina, de $33 \mathrm{Km}$ de longitud, están conectados con la Vía Verde de Alcaraz. Como elemento integrador se ha construido en la ciudad de Albacete un centro de interpretación del agua en un antiguo depósito de mitad del siglo XX situado en el paraje de La Fiesta del Árbol. Los ejes viarios atraviesan en este caso la histórica comarca de la Mancha de Montearagón, en la que la horizontalidad es la nota dominante, donde la llanura es casi perfecta, rota solamente en las proximidades de la ribera del Júcar, donde el río se ha encajado labrando un profundo valle.

\section{c) La ribera del río Júcar}

Una de las unidades paisajísticas más representativas de la provincia de Albacete es la que aparece asociada al Río Júcar, que ha labrado un profundo cañón sobre calizas y dolomías, de paredes casi verticales en algunos tramos. El Júcar deja una vega estrecha y encajonada de regadíos históricos y una vegetación de ribera característica. Sobre este entorno de elevado valor ambiental y paisajístico, la Consejería 
de Agricultura de la Junta de Comunidades de Castilla-La Mancha, a través de Dirección General de Desarrollo Rural, ha acondicionado un eje viario que discurre paralelo al cauce del río, y que da servicio a los agricultores, pero es también una vía turística que se abre a un cauce con espacios escénicos asociados al río, a su vega y a los escarpes encañonados de sus paredes. El recorrido va paralelo al río y enlaza con otros carriles que conectan con los canales de María Cristina. Cuenta con paneles explicativos y barandillas laterales. Deja lugares de estancia cerca del núcleo de Valdeganga y en las inmediaciones de la antigua presa de Bolinches (el Charco Azul), nacidas en este caso de actuaciones de la Confederación Hidrográfica del Júcar. También la Confederación ha acondicionado algunos ejes en las inmediaciones del paraje de las Mariquillas, en los que incluso aparece una réplica de una antigua noria, que daba vida a la economía hortícola de la vega.

Aguas abajo, a la altura de La Recueja y Alcalá del Júcar, y siguiendo el trazado del curso fluvial, la Confederación Hidrográfica, ha llevado a cabo actuaciones de mejora de la ribera a su paso por los núcleos urbanos. Destaca la realizada en las faldas del escarpe rocoso en que se emplaza el histórico núcleo de Alcalá del Júcar. En estos casos se han realizado tareas de recuperación y acondicionamiento del cauce, pero también del entorno (riberas, puentes, creación y delimitación de zonas de paseo y estancia...).

\section{d) Las cañadas y vías pecuarias}

La administración regional ha realizado actuaciones orientadas a recuperar y reaprovechar terrenos públicos, supuestamente ocupados por agricultores. Entre estas destacan deslindes, amojonamientos y acondicionamiento de vías pecuarias para uso turístico recreativo. Se trata de un proceso que no ha concluido, pero que en algunos sectores de la provincia ha posibilitado que cañadas y cordeles puedan destinarse a uso turístico y recreativo (que ya no pecuarios).

Las actuaciones se han concentrado especialmente en el entorno de la ciudad de Albacete, y han convertido algunos tramos de antiguas vías pecuarias en rutas de senderismo y cicloturismo. Se ha adaptado el tramo de cañada real que va desde la ribera del río Júcar hasta las inmediaciones de la ciudad de Albacete como zona de uso para peatones y bicicletas, lo que permite el recorrido desde antiguos bosques de pinares en buen estado de conservación, en la ribera del río Júcar, hasta la histórica villa de Chinchilla de Montearagón. También se han recuperado tramos de un antiguo cordel que corre paralelo a las vías del tren de Alta Velocidad, que tiene ahora un uso recreativo y que es resultado de los trabajos de mejora encomendados a empresas adjudicatarias de obras públicas de cierto calado (estación ferroviaria del AVE limpieza del Canal de María Cristina entre Albacete y Valdeganga). 


\section{e) La red de miradores}

Otro de los elementos empleados para uso y disfrute (también consumo) del paisaje es la creación de miradores, que se convierten en ventanas a espacios de valor ambiental y escénico. Su acondicionamiento ha sido responsabilidad de las administraciones encargadas de la construcción y mantenimiento de la red de carreteras (especialmente regional y provincial). También están localizados en parques naturales, $\mathrm{y}$ han nacido del interés de sus gestores por controlar el acceso, y sobre todo de revalorizar los enclaves de especial valor paisajístico. Generalmente llevan asociados aparcamientos y zonas de estancia, y cuentan con accesos acondicionados. En algunos casos se acompañan de paneles explicativos. Un parte de ellos se localizan en la Sierra del Segura. Otros en las carreteras que recorren la ribera del río Júcar. El primer grupo tiene por objeto descansar la mirada en enclaves singulares, en su mayor parte abiertos a los vigorosos relieves terciarios, labrados sobre calizas, en la Sierra de Segura. Sobre ellos el Leader Sierra del Segura ha puesto en marcha un programa de paneles explicativos. Otros se reparten por la ribera del Júcar, y en este caso se ubican en espolones elevados que se abren al valle, y dejan escenarios espectaculares, que integran paisajes asociados al río, a su vega, al cañón labrado por el río, y a la llanura en la que se ha encajonado el Júcar.

A partir de este grupo de instrumentos de uso del paisaje se han intentado crear algunas rutas temáticas al amparo de recursos patrimoniales o culturales, que se mantienen latentes o han quedado a la espera de nuevas oportunidades. En todas ellas el paisaje aparece como elemento estratégico en su conformación (rutas del Quijote, de Vandelvira, Santiaguista, del camino de Santiago, pruebas deportivas...). También apoyado en el paisaje ha surgido un proyecto ambicioso, el de un ecomuseo en la Sierra de Alcaraz, cuyo elemento vertebrador, además del patrimonio cultural, histórico y arquitectónico, son los paisajes de la comarca. Se complementa todo ello con una red tupida de senderos (GR yPR) destinados a un público con preferencias mucho más específicas.

\section{CONCLUSIONES}

Los espacios rurales se han convertido en la última década en lugares de ocio y turismo, aunque ha sido un redescubrimiento selectivo en lo territorial. También lo ha sido en la tipología de recursos puestos en valor. Algunos enclaves han cobrado protagonismo y significación. De hecho se han convertido en los principales reclamos para los visitantes. El proceso ha estado en correspondencia con los cambios y preferencias de un colectivo creciente de turistas, que entiende el medio rural como ámbito de turismos (en plural, porque son diferentes las tipologías que aparecen). Sobre ellos se han realizado acciones desde las diferentes administraciones para mejorar el entorno, facilitar el uso recreativo, y convertir en accesible el territorio turístico a través de rutas, miradores o espacios de estancia. Han sido sobre todo los paisajes del agua los grandes beneficiados, que cuentan con una especial carga ambiental, cultural y sensorial (lagunas, cursos hidrográficos encañonados...). 
En el proceso de puesta en valor del paisaje queda un conjunto de iniciativas relativamente recientes, voluntaristas en la mayor parte de los casos, improvisadas generalmente y descoordinadas muchas de ellas. Han surgido en su totalidad desde actores públicos, que han abierto rutas de senderismo o miradores, convertidos ahora en corredores o nodos paisajísticos destinados al uso turístico. En ocasiones han supuesto actuaciones acertadas. En otros casos pueden cuestionarse, porque se han hecho sin tener en cuenta las preferencias de los turistas o el propio valor de los recursos. Sí que es cierto que han nacido con la filosofía de recuperar antiguos ejes viarios, independientemente del valor paisajístico de su entorno. A su amparo han surgido microcircuitos y rutas que incluyen repertorios paisajísticos. Como resultado más palpable queda un incremento en el aprovechamiento social y turístico del paisaje. En algunos casos se está contribuyendo a generar escenografías ambientales que aparecen de manera recurrente en los nuevos medios de relación (internet especialmente), y que los convierten en paisajes luminosos, visibles, conocidos por los turistas y los visitantes, reconocidos también por la administración... Son escenarios que se han convertido en turísticos y que en su entorno dejan iniciativas empresariales -microempresariales- (alojamientos rurales, restaurantes, campings, balnearios, puntos de venta de productos típicos, carteles informativos, centros de interpretación...). Se han convertido en escenarios singulares y atractivos, en microdestinos que sirven de soporte a un sector turístico emergente. Son los protagonistas indiscutidos del redescubrimiento de lo rural. Las formas en que esto se materializa son diversas y están sujetas a procesos acelerados y cada vez más intensos, con efectos territoriales muy nítidos. A distancia de ellos quedan traspaíses turísticos, al margen de esas escenografías, a los que no llegan estas actividades, y que mantienen su condición y esencia de ruralidad alta, sin apenas beneficios del turismo. Entre unos y otros quedan interfaces, zonas de transición, en las que el turismo comienza a dejarse sentir, aunque de forma incipiente, cuyo desarrollo está condicionado a la aparición y apertura de rutas que posibiliten el acceso y uso paisajístico de estos enclaves. Las conexiones entre lo que el turista demanda y lo que la administración ofrece requieren de una revisión en cuanto a métodos de trabajo, objetivos, y sobre todo identificación de las potencialidades turísticas del territorio y de asignación de un protagonismo mayor al paisaje como elemento catalizador de una modalidad, la del turismo rural, en auge.

Pero es evidente también que determinados territorios requieren protección y sobre todo cautela en su proceso de conversión en recursos turísticos, porque un uso excesivo e incontrolado puede repercutir en negativo, tanto en los valores ambientales y paisajísticos del recurso, como en la propia pervivencia de futuro de un turismo que consume y utiliza el paisaje como recurso principal, pero sin que exista una conciencia clara de su valor y potencialidades. 


\section{BIBLIOGRÁFIA}

AECIT (varios años). La actividad turística española. Asociación Española de Expertos Científicos en Turismo, Fundación Ramón Areces. Madrid.

ANTÓN, S. (2005). "Turismo rural y territorio". XI Congreso de Turismo Rural de Asetur. Cangas de Onís. Principado de Asturias.

BOSCH, R. et alt. (1998). Turismo y medio ambiente. Centro de Estudios Ramón Areces. Madrid.

BOTE, V. (1995). La demanda turística española en espacio rural o de interior: situación actual y potencial. Instituto de Economía y Geografía del CSIC. Madrid. Documento de trabajo.

CABERO, V. (2004). "El paisaje en la Geografía española actual". En Ortega, N: (coord.): Naturaleza y cultura del paisaje. Universidad Autónoma de Madrid. Madrid.

CÁMARA DE COMERCIO DE ALBACETE (2006). Estudio del mercado turístico de la provincia de Albacete. Serie Estudios Turismo, $n^{\circ} 1$. Cámara de Comercio de Albacete. Albacete.

CÁMARA DE COMERCIO DE ALBACETE (2008). Análisis comarcal de la oferta turística de Albacete. Perspectiva de la demanda. Serie Estudios turismo, $n^{\circ} 2$. Cámara de Comercio de Albacete. Albacete.

CÁMARA, J. (Dir.) (2005): Ruta de Don Quijote. Un lugar para la aventura. JCCM. Toledo.

CEBRIÁN, A. (2003). "Génesis, método y territorio del desarrollo rural con enfoque local”. Papeles de Geografía, no 38, pp 61-76.

CEBRIÁN, F. (2011). "Los ferrocarriles olvidados. Reconversión y reinvención como instrumentos de revitalización recreativa y turística: el Baeza-Utiel a su paso por la provincia de Albacete". Revista Cuadernos de Turismo, $\mathrm{n}^{\circ}$ 27; Universidad de Murcia. Pp 205-225.

CONFEDERACIÓN HIDROGRÁFICA DEL JÚCAR (2009). Proyecto de restauración del tramo medio-alto del río Jardín e integración con el entorno de la laguna de los Ojos de Villaverde (de Robledo a Casas de Lázaro). Documento Ambiental. http://www.chj.es/es-

es/medioambiente/proyectos/Paginas/DescargaDocumentosAmbientales.aspx?codi go $=08.411 .310 / 2111$.

COLEGIO DE GEÓGRAFOS (2006). Manifiesto por una Nueva Cultura del Territorio. Colegio de Geógrafos. Marzo 2006.

CONSEJO DE EUROPA (2000). Convenio Europeo del Paisaje. Florencia, 20 de octubre de 2000.

CROSBY, A. (1994). Interpretación ambiental y turismo rural. Centro Europeo de Formación Ambiental y Turismo. Pamplona.

ESPARCIA, J.; NOGUERA, J. (1999). "El concepto de desarrollo y su influencia en la consolidación de los desequilibrios espaciales". Revista Cuadernos de Geografía, no 65-66; pp 231-254. 
FUNDACIÓN FERROCARRILES ESPAÑOLES (2008). Proyecto constructivo para el acondicionamiento del trazado de ferrocarril en desuso Baeza-Utiel (tramo el Jardín-Santuario de Cortes) para su uso como Vía Verde de la Sierra de Alcaraz. Junta de Comunidades de Castilla-La Mancha, Diputación Provincial de Albacete, Fundación de Ferrocarriles Españoles.

GARCÍA, J.A. (2009). Análisis cartográfico del turismo oculto en la provincia de Albacete. Tesis doctoral. Departamento de Geografía. Universidad de Castilla-La Mancha.

IVARS, J.A. (2000). "turismo y espacios rurales: conceptos, filosofías y realidades". Revista Investigaciones Geográficas, $\mathrm{n}^{\circ}$ 23, pp 59-88.

JUAN, F.; Solsona, J. (2000). Alojamiento turístico rural. Gestión y comercialización. Editorial Síntesis. Madrid.

LIBRO VERDE sobre la cohesión territorial. Comisión de las Comunidades Europeas.http://ec.europa.eu/regional_policy/consultation/terco/index_es.htm

LÓPEZ PALOMEQUE, F. (2008). Delimitación conceptual y tipologías del turismo rural. En Pulido, J.A. (Coord.) (2008). El turismo rural. Editorial Síntesis. Madrid.

MARTÍNEZ DE PISÓN, E.; 2005: "el paisaje como encuentro y expresión de la identidad. Literatura, expresionismo y protección". En Ortega, N. (edit.): Paisaje, memoria histórica e identidad nacional. Ediciones UAM y Fundación Duques de Soria. Madrid.

MATA OLMO, R. (Coord.) (2008). Atlas de los paisajes de España. Ministerio de Medio Ambiente. Madrid.

MATA OLMO, R. (2010). "La dimensión patrimonial del paisaje. Una mirada desde los espacios rurales". En Serrano, A et alt (edit.). Crisis y territorio. Aportaciones y conclusiones del VI Congreso Internacional de Ordenación del Territorio. Fundicot. Pamplona. Pp 343-366.

MESA, M. (2000). "El turismo rural y el desarrollo local”. En Pérez, B. y Carrillo, E.: Desarrollo local. Manual de uso. Federación Andaluza de Municipios y Provincias y Editorial ESIC. Madrid. Pp 555-599.

MUÑOZ, F. (2010). "Paisaje y patrimonio territorial en un escenario de cambio global. Nuevos retos y perspectivas". En Serrano, A et alt. (edit.): Crisis y territorio. Aportaciones y conclusiones del VI Congreso Internacional de Ordenación del Territorio. Fundicot. Pamplona. Pp 311-327.

NOGUÉ, J.; SALA, P. (2006). Prototipo de catálogo de paisajes. Bases conceptuales, metodológicas y procedimentales para la elaboración de los catálogos de paisaje en Cataluña. Documento de referencia para los grupos de trabajo. Olot y Barcelona.

OLIVARES, D. (2008). "Factores de localización espacial del turismo rural". En Pulido, J.A. (Coord.) (2008): El turismo rural. Editorial Síntesis. Madrid.

ORTEGA, M. (2010). Paisaje y patrimonio territorial. En Serrano, A et alt (edit): Crisis y territorio. Aportaciones y conclusiones del VI Congreso Internacional de Ordenación del Territorio. Fundicot. Pamplona. Pp 343-366. 
ORTEGA, N. (2004). "Naturaleza y cultura en la visión geográfica moderna del paisaje". En Ortega, N. (edit.): Naturaleza y cultura en el paisaje. Edición UAM y Fundación Duques de Soria. Madrid.

PILLET, F (1997). "El turismo de interior como nueva fase de desarrollo local". En Valenzuela, M. (Coord.): Los turismos de interior. El retorno a la tradición viajera. Universidad Autónoma de Madrid. Madrid.

PÉREZ, M. (1997). “Turismo rural sostenible”. Revista de Desarrollo Rural y Cooperativismo Agrario, $\mathrm{n}^{\circ}$ 1, pp 181-186.

PONS, B. (Dir.) (2011). Atlas de los paisajes de Castilla-La Mancha. Ediciones de la Universidad de Castilla-La Mancha. Ciudad Real.

PULIDO, J.I. (2008) (coord.): Turismo rural. Editorial Síntesis. Madrid.

SANCHO, J.; Panadero, M. (edit.) (2004). Atlas del Turismo Rural de Castilla-La Mancha. IGN, UAH, UCLM: Madrid.

VALENZUELA (Coord) (1997). Los turismos de interior. El retorno a la tradición viajera. Ediciones Universidad Autónoma de Madrid. Colección Estudios. AGE. Obra Social CCM. Madrid.

VERA, J.F. (1997). Análisis territorial del turismo. Ariel Geografía. Madrid.

VERA, J.F.; SANCHO, J. (2008). Atlas nacional de España. Turismo en espacios rurales y naturales. CNIG. IGN. Madrid. 